\title{
DINÁMICA EN EL USO DE LOS RECURSOS NATURALES EN EL ORIENTE DE YUCATÁN DURANTE EL SIGLO XX
}

\author{
NATURAL RESOURCE USE IN EASTERN YUCATÁN \\ DURING THE TWENTIETH CENTURY
}

Miguel Ángel Pinkus Rendón

Centro Peninsular en Humanidades y en Ciencias Sociales

Universidad Nacional Autónoma de México

mapinkus@humanidades.unam.mx

\section{RESUMEN}

Desde la historia ambiental y mediante una revisión minuciosa y complementaria de la literatura existente y de la historia oral, este artículo ofrece una revisión histórica de los diferentes usos de suelo en el oriente de Yucatán a lo largo de 100 años, para identificar y describir distintos eventos económicos y sociales que han transformado la región, afectado la economía de las comunidades humanas que la habitan. En este sentido, se hace un recuento de las actividades productivas que han explotado recursos naturales propios de la zona (madera, chicle, sal) y de aquellas que han introducido especies de flora y fauna ajenas, con el respectivo impacto negativo en el paisaje (ganadería y cultivo de pastos para esta actividad). Se incluyen también factores sociales como la migración interestatal, que han influido en el manejo del entorno.

PALABRAS CLAVE: sureste de México, paisaje, impacto antropogénico, uso del suelo.

\section{ABSTRACT}

From the perspective of environmental history, based on a thorough and complementary review of the existing literature as well as oral history, this article offers a historical review of the different land-uses in Eastern Yucatán State throughout 100 years. The purpose of this review is to identify and describe the different economic and social events that have transformed the region, thus affecting the economy of local communities. It describes the productive activities that have exploited the region's natural resources (wood, gum, and salt), as well as those productive activities that have introduced alien flora and fauna species with the corresponding negative impact on the land (cattle-raising and the cultivation of pasture). It also includes social factors such as interstate migration, which have influenced the way surroundings have been managed.

KEY WORDS: South East México, landscape, anthropogenic impact, land-use. 


\section{INTRODUCCIÓN}

S e ha demostrado que el cambio en el uso del suelo y la fragmentación de los paisajes repercuten en los organismos que en ellos habitan, ya sea reduciendo sus poblaciones, cambiando la composición y estructura de las comunidades biológicas o influyendo en la diversidad a nivel paisaje (Forman 1999, Summerville y Thomas 2001). Asimismo, este cambio puede ser bidireccionado, ya que si bien se modifica el paisaje natural y los organismos asociados por la intervención humana, la naturaleza a su vez también impacta de regreso en los grupos sociales. Es decir, la disponibilidad de los recursos naturales presentes después de una modificación en el uso del suelo será diferente a la que se vislumbraba previamente a este proceso.

En México, aunque el fenómeno descrito se ha presentado fuertemente en todo el territorio, se ha remarcado más en el sur y sureste del país, debido a que en estas regiones se ha encontrado una mayor biodiversidad, además de presentar los sitios más conservados en cuanto a tipos de hábitats se refiere (Pinkus et al. 2006).

En este sentido, el paisaje de Yucatán ha tenido un proceso paulatino de transformación por diversas razones (económicas, naturales y sociales), desde la época prehispánica hasta la actualidad. Particularmente, el oriente del estado, cuyos municipios comprenden (de norte a sur) Río Lagartos, Tizimín, Calotmul, Temozón, Valladolid y Chemax, es donde se podrían ejemplificar varios de estos cambios ambientales que influyen a su vez en las transformaciones sociales y culturales (figura 1).

Después de Mérida, capital del estado (que concentra $42 \%$ de la población total de la entidad), el oriente es una de las regiones más importantes, por varias razones: primera, porque ahí se ubican dos de los municipios con mayor número de habitantes, después de Mérida: Tizimín y Valladolid (7\% del total del estado); segunda, porque estos municipios son los que tienen los mayores ingresos brutos captados por impuestos, derechos, participaciones federales y estatales, sumando para 2007, respectivamente, \$140 575549 y \$120 013441 (INEGI 2009). A su vez, Tizimín es el municipio con mayor extensión territorial (aproximadamente 413237 ha) en el estado, por lo cual posee una gran diversidad de hábitats tanto naturales como antropogénicos. 
Figura 1 Región de estudio. Elaboración propia.

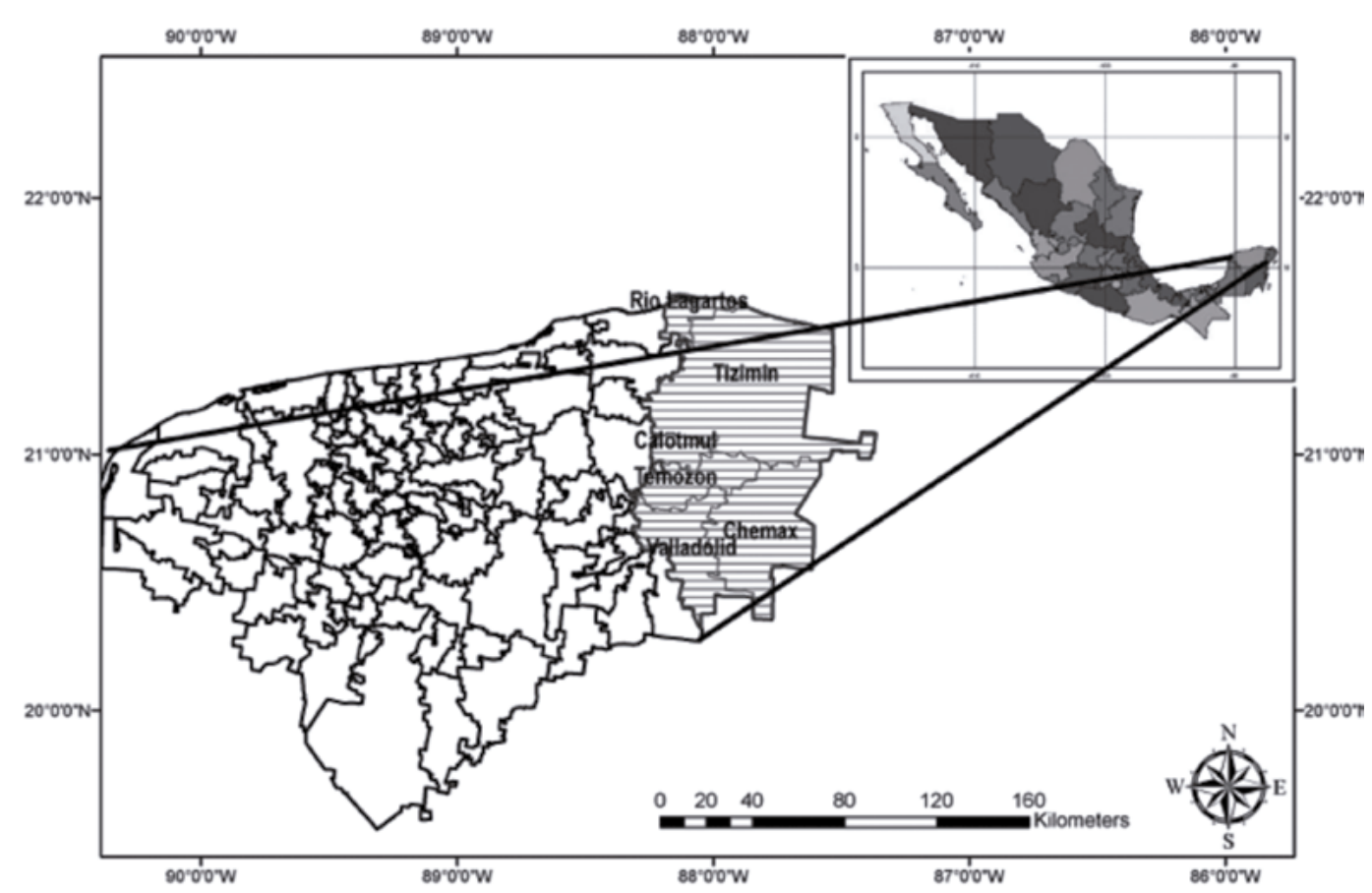

Históricamente, la región ha sido sometida a múltiples transformaciones tanto ambientales y económicas como sociales. En el primer aspecto se ha observado un cambio en el uso del suelo de una gama de sistemas naturales, ya que ciertas áreas donde había una vegetación primaria o prístina de selvas bajas y medianas en la parte colindante con el estado de Quintana Roo, o manglares en la costa y parte media, dunas y selvas inundables, se han visto parcialmente transformadas en tierras de cultivo o lugares de extracción de maderas y sal.

Desde la época prehispánica se ha tenido un impacto en el ecosistema por la práctica del sistema de roza, tumba y quema (RTQ) como método de manejo agrícola, que dependiendo el tamaño de la población era la perturbación que provocaban en el paisaje (Challenger 1998). Se ha argumentado que este sistema era de bajo impacto, debido a que se rotaban las áreas de manejo cada 20 a 25 años, además de que se utilizaba una gran diversidad de especies en este agroecosistema, apuntalado principalmente en el cultivo de maíz (Zea mays), calabaza (Cucurbita moschata) y frijol (Phaseolus vulgaris) (Terán y Rasmussen 1994, 
Toledo et al. 2008). Este sistema ha perdurado hasta nuestros días con sus respectivas modificaciones como lo abordaré posteriormente.

Si bien desde ese entonces se provocaban modificaciones del paisaje, con la presencia española se generaron otros usos del suelo. La actividad ganadera fue introducida en el periodo colonial. Comenzó alrededor de los poblados donde se iban asentando y concentrando las encomiendas; sin embargo, no fue hasta la entrada de los monocultivos, aserraderos y ganadería extensiva cuando se acrecentó la fragmentación de los terrenos. En este sentido, a finales del siglo XVIII y hasta la mitad del XX el cultivo del henequén (Agave fourcroydes) fue abarcando grandes extensiones del territorio yucateco (Machuca-Gallegos 2010), sobre todo en aquellos lugares donde existía vegetación de selva baja caducifolia. De esta planta se extraía una fibra muy resistente, útil en la fabricación de cuerdas, tapetes y otros productos. Las haciendas henequeneras tuvieron auge debido a que se utilizaban en los Estados Unidos, en las engavilladoras de trigo, máquinas que no solo cosechaban, sino que al mismo tiempo amarraban los fardos de paja. Con la demanda que tenía este agave y el desarrollo ferroviario que se impulsaba, las haciendas henequeneras llegaron a ubicarse prácticamente en todo el estado, incluso en los municipios del oriente, aunque en menor medida que en el centro, lo que provocó casi la desaparición de las selvas secas (figura 2). No obstante, en el siglo XX, con la aparición de las fibras sintéticas se fueron abandonando tanto el uso del henequén como las propias haciendas, pasando por un tortuoso camino de estatización y su eventual y paulatino abandono.

Por otro lado, se presentaron cambios sociales que impactaron no solo en la región oriental, como lo fue la separación, en 1861, de Campeche y Yucatán como dos estados independientes. No obstante, el acontecimiento que dejó una huella histórica tanto a nivel local como nacional fue la llamada guerra de castas, que se vivió a mediados del siglo XIX. Ese conflicto bélico en que se enfrontaron grupos de ascendencia maya se asumió como una revuelta étnica entre los mayas cruzoob y los «blancos», o no mayas. Entre los primeros, según Sweeney (2006:13), se incluían caciques, contrabandistas, comerciantes, campesinos y exmilitares contra los distintos órdenes de gobierno de Yucatán y del desarrollo económico que favorecía a los terratenientes y muy poco al campesinado. Los rebeldes pedían la disminución de las contribuciones civiles y religiosas, el establecimiento de milpas en los terrenos baldíos y la cancelación de la deuda de los

\footnotetext{
${ }^{1}$ Los mayas rebeldes eran asociados con ese vocablo, que integraba la palabra española cruz ligada con la leyenda según la cual una cruz parlante guió a los mayas a luchar contra los opresores, y la palabra oob, que es la marca de plural en la variante regional de lengua maya.
} 
peones de las haciendas. Fue así como los indígenas orientales lucharon contra todo lo que consideraban «español» (en un acto identitario). Sin embargo, en vez de tomar en cuenta las demandas de este grupo, las fuerzas estatales, y posteriormente las federales, enviaron regimientos para lidiar contra los insurrectos, a los que se persiguió y abatió. Algunos de los que se salvaron lograron huir a las tierras del actual estado de Quintana Roo, en la profunda selva. Por ello, las comunidades de la región oriental son las que destacan por su tradición maya. Es decir, conforme a Ramírez (2003), es ahí donde todavía se conservan los antiguos sistemas de toma de decisiones y arreglos de la vida comunal, por medio de asambleas o de elecciones colectivas, así como la estructura de posiciones

Figura 2. Península de Yucatán. Tomado de Taracena y Pinkus 2010.

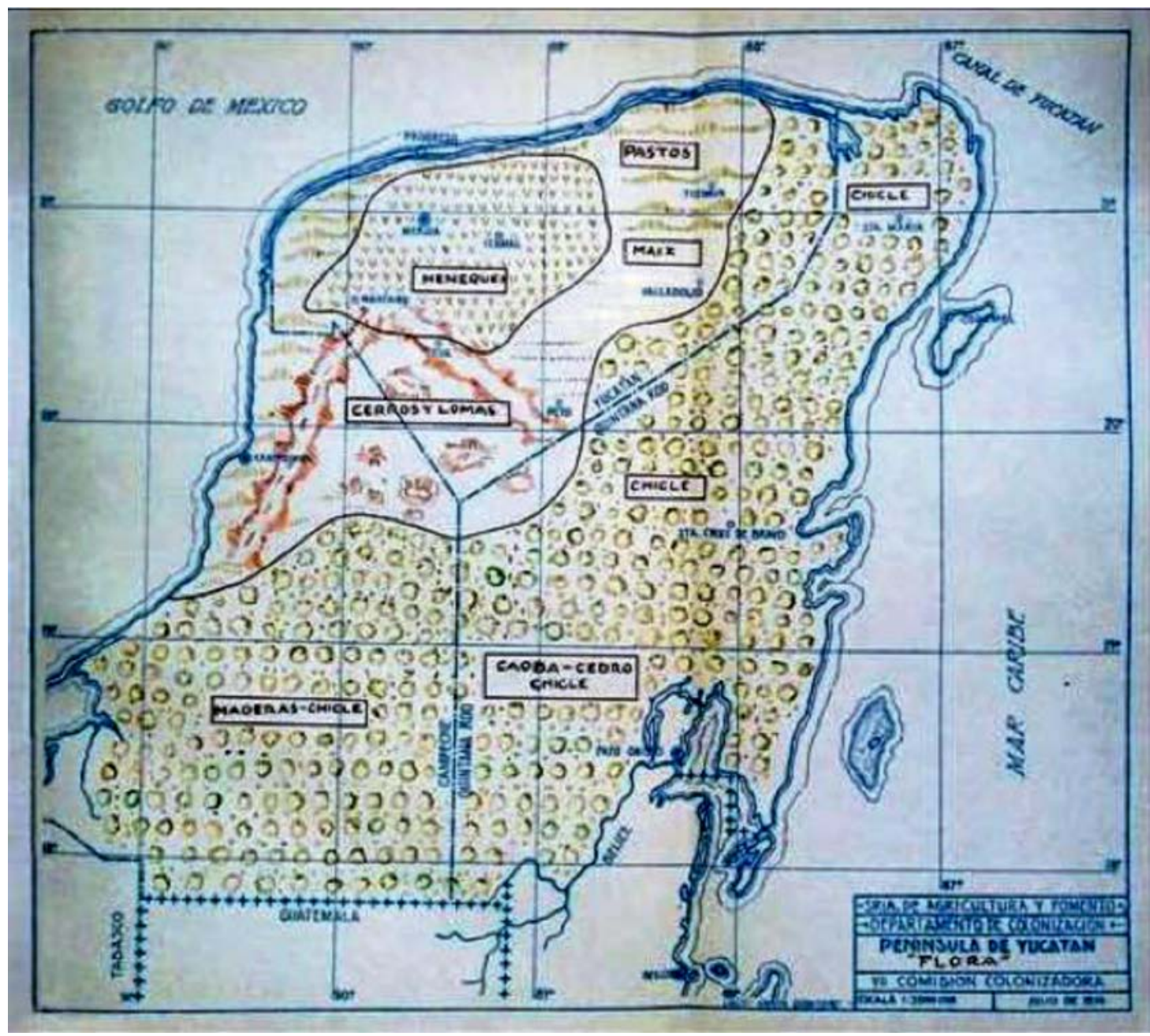


de poder impuesta sobre la comunidad. Ejemplo de ello es el pueblo de Xocén (comisaría de Valladolid), donde se conservan sistemas tanto de defensa, similares a los practicados durante la guerra de castas, como de creencias; de hecho, la «Cruz Parlante» utilizada para incentivar a la guerrilla durante dicho episodio histórico es originaria de esa población (Terán y Rasmussen 2005).

La combinación de estos acontecimientos durante el siglo XIX, más los grandes avances de las fincas henequeneras, los cortes de chicle y maderas preciosas, promovieron un vuelco económico local, ya que los acaudalados necesitaban la mano de obra que era monopolizada por los pobladores de la región, al igual que el uso de los recursos naturales. Dichas actividades eran muy mal remuneradas y los pobladores siempre eran embaucados por los enganchadores que se encargaban de atraer a los peones y endeudarlos para que no abandonaran esas tareas (Montalvo y Vallado 1997). Por tal motivo, en este estudio se plantea identificar y describir cómo, a lo largo de 100 años, distintos eventos económicos y sociales han transformado los paisajes de la región oriente del estado y afectado la economía de las comunidades que la habitan, llevándolas a una pobreza de recursos naturales, en el marco de las actividades primarias de la población campesina.

En este sentido, el paisaje sería un mosaico de parches de distintos hábitats, considerando estos desde ecosistemas naturales, agroecosistemas o hábitats antropogénicos (zonas urbanas o suburbanas), en tanto que la región podría ser entendida como el territorio con características históricas y culturales semejantes en el cual confluyen varios paisajes.

\section{MARCO CONCEPTUAL Y METODOLÓGICO}

El presente trabajo se enmarcó en el enfoque metodológico de la historia ambiental, que como bien señala Leff (2004:134):

abre una nueva indagatoria sobre el tiempo, sobre las temporalidades que definen a los procesos ecológicos y a las identidades culturales que se hibridan con los procesos económicos y tecnológicos. La historia ambiental será el encuentro de racionalidades diferenciadas para cuyo abordaje, la definición genérica del ambiente como el campo de las relaciones sociedad-naturaleza ofrece tan sólo una primera puerta de entrada al estudio de sus complejas interrelaciones. La historia ambiental se ha venido definiendo como un campo de estudio de los impactos de diferentes modos de producción 
y formaciones sociales sobre las transformaciones de su base natural, incluyendo la sobrexplotación de los recursos naturales y la degradación ambiental. Estos estudios abordan el análisis de patrones de uso de los recursos y de formas de apropiación de la naturaleza, avanzando en categorías que permiten un estudio más integrado de las interrelaciones entre las estructuras económicas, políticas y culturales que inducen ciertos patrones de uso de los recursos y las condiciones ecosistémicas que establecen las condiciones de sustentabilidad o de insustentabilidad de un territorio determinado.

Es así que se busca entender la conversión ambiental del oriente yucateco del siglo XX, así como parte de las causas y los impactos sociales y económicos que comprendió.

Para documentar cómo fue transformándose el oriente de Yucatán, se realizó una búsqueda bibliográfica exhaustiva respecto de los diferentes usos del suelo desde principios del siglo XX hasta el presente, incluyendo censos poblacionales y agropecuarios. Asimismo, se examinó la cartografía histórica de las principales actividades económicas que se desarrollaron en ese periodo.

Se recurrió además a la historia oral para completar lo encontrado en las referencias y en los mapas, así como para explicar por qué se dieron los cambios que nos ocupan. Para ello se realizaron entrevistas semiestructuradas de junio de 2012 a enero de 2013 en lo tocante a la historia ambiental en los diferentes sitios de estudio. Los informantes entrevistados eran pobladores mayores de 60 años nacidos en esos sitios o con más de 20 años de residir ahí. Se pretendía indagar cómo eran los tipos de vegetación y cuáles eran las actividades económicas que se llevaban a cabo en las décadas previas, tratando de hacer una cronología de los usos y manejos del entorno.

\section{RESULTADOS Y DISCUSIÓN LA EXPLOTACIÓN CHICLERA}

Una de las actividades productivas relevantes durante las primeras décadas del siglo XX en el oriente yucateco fue el corte del chicle. Este producto se obtiene de la planta del zapote (Manilkara zapota). El consumo de esta resina se practica desde la época prehispánica. Y según referencia anecdótica, fue debido al encuentro de Antonio López de Santa Anna y James Adams que se dio a conocer de manera global la explotación de este producto (Rivera-Ayala 2001), ya que, se dice, encontraron a una persona masticando la goma y le pidieron que señalara 





de dónde la extraía y cómo la consumía. Y en ese momento James Adams tuvo la idea de que este producto podría comercializarse, tanto en México como en otros países. Fue así como empezó su aprovechamiento comercial, desde finales del XIX, en las selvas tropicales de Veracruz, y en pocos años fue extendiéndose a toda la península de Yucatán, ya que en esta región los árboles de chicle abundan de manera natural.

La práctica consistía llegar a extensiones de selva con alta densidad de árboles de zapote, y colocar campamentos semipermanentes. Los cortadores subían a los individuos más grandes, a fin de poder extraer la mayor cantidad de resina, mediante incisiones en la corteza (existían varias técnicas) y colocaban bolsas al pie del árbol para recolectar la resina que bajaba. Dichos cortes se hacían por capas, para que pudieran realizarse otros tajos en futuras incursiones (PonceJiménez 1990).

Si bien la extracción del chicle no representó una actividad con un gran impacto ambiental, sí ejerció presión entre la población que podía establecerse en estos campamentos chicleros, ya que por más de 50 años se trasladaban a la selva contingentes de cortadores, personas que hervían el chicle y cocineros. En ocasiones, familias enteras iban a la selvas en época de corte y al terminar regresaban a sus pueblos. Pobladores de los municipios de Chemax, Valladolid y Tizimín se movían a los manchones de selvas que aún tenían, y comentaban que incluso iban a cortar chicle en el estado aledaño de Quintana Roo, en las inmediaciones de Akumal, que a principios del siglo XX mantenía poblaciones muy pequeñas. Esta migración interestatal para la explotación del chicle la dejaron de realizar cuando se repartieron tierras ejidales en el entonces territorio de Quintana Roo. La chiclería se mantuvo por varias décadas, aunque la mayor producción se dio entre 1925-1930 y 1939-1940 (Ponce-Jiménez 1990), bajando drásticamente en el momento que apareció la goma de mascar sintética, y se fue reduciendo hasta quedar solo en el recuerdo de los antiguos cortadores o enganchadores.

\section{LA INDUSTRIA MADERERA}

Otra ocupación que representó el uso y manejo de recursos naturales por parte de los pobladores fue el corte de madera. Ha sido una actividad constante desde hace varios siglos. En un principio las especies con utilidad y con potencial económico fueron aquellas de las que se podían extraer tinturas, como el añil 
(Indigofera suffructicosa) y el palo de tinte (Haematoxylum campechanium), que daban colorante azul y rojizo, respectivamente. Su explotación dejó grandes dividendos a la Corona española (Ruz 1979). La gran mayoría de estas mercancías eran embarcadas y enviadas rumbo al viejo continente, y aunque en el traslado se daban muchos acontecimientos de piratería, la actividad perduró hasta el siglo XIX. De hecho, el pirata William Dampier (1789) escribió acerca del corte del palo de tinte y de la manera de vivir que tenían los cortadores de los tintales.

Otras especies extraídas desde el siglo XVIII fueron las consideradas maderas preciosas, tales como el cedro (Cedrella odorata) y la caoba (Swetenia macrophy(la), cuyo intercambio con el viejo continente fue tan importante que incluso se dio en contrabando al final de la colonia (Pinet 1998).

Estas especies de árboles son propias de las selvas, desde secas hasta húmedas, donde, conforme aumenta la profundidad del suelo y humedad ambiental también se da un aumento en el tamaño de los ejemplares. Y su explotación fue retomada mucho tiempo después, en el oriente de Yucatán, debido a que por las condiciones ambientales y por la conservación del entorno se podía encon-

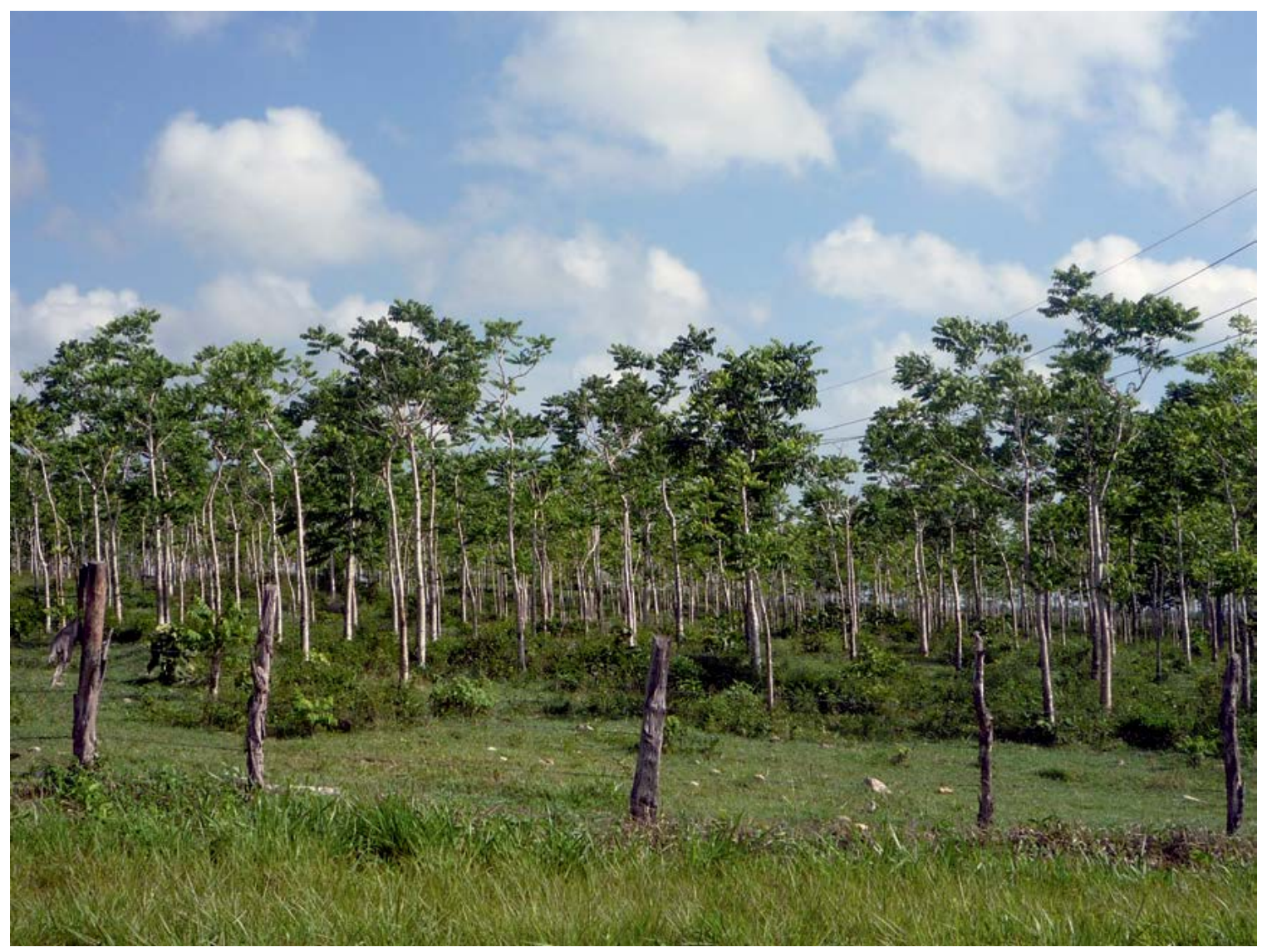


trar una alta densidad de maderas preciosas, sobre todo de cedro, a la par de la explotación del chicle. En el noreste, particularmente en lo que se denominó Colonia Yucatán, el empresario Alfredo Medina Vidella comenzó la explotación del cedro rojo, primero con 100000 ha de terreno virgen, llegando a alcanzar más de 389000 metros cúbicos de madera durante el quinquenio 1941-1945 (Ruiz-Silva 2011). Con la apertura de la concesión de explotación forestal fue aumentando la extensión de tierra utilizada para el corte de madera, así como la ampliación en las especies que se cortaban, en donde — según relatos de los entrevistados- se incluyó prácticamente todo tipo de madera, ya que se producían tablas, tablones, reglillas o simplemente se usaba para formar el corazón del triplay.

La empresa Maderera del Trópico tuvo su esplendor entre los años de 1945 a 1965, aunque en 1951 su fundador renunció en rechazo a la injerencia del gobierno federal. En la época del gran auge se abrió otro campamento maderero en Zoh Laguna, Campeche. Incluso se tuvo que habilitar un puerto en el Cuyo, Yucatán, para transportar la madera vía marítima y llevarla a Veracruz, y de allí a la Ciudad de México (Ruiz-Silva 2011). Sin embargo, la tala inmoderada a gran escala empezó a abarcar todo el municipio de Tizimín (el más grande del estado), incluidos los municipios aledaños; y según los informantes, se abusó a tal grado que acabaron con la madera y tuvieron que empezar a importarla de Brasil. Así, al grave deterioro ambiental se sumó un mayor costo de producción de tablones por la introducción de maderas extranjeras. Estos hechos, aunados a la injerencia gubernamental y el cambio en el uso del suelo, de silvícola a ganadero, hicieron que en 1975 cerrara la empresa forestal y con ella se diera vuelta a la página de la historia del uso de recursos maderables del oriente de Yucatán.

\section{LA GANADERÍA}

A consecuencia del declive de sendas actividades productivas, como la henequenera y el corte de madera para la manufactura de tablas, los pobladores del oriente tuvieron que buscar opciones. Si bien el manejo de ganado vacuno fue introducido por los españoles durante la época colonial (Challenger 1998), y tuvo un papel importante durante la colonia y el siglo XIX como hacienda ganadera acompañada de la hacienda maicera (Machuca 2011), no es sino hasta la mitad del siglo XX cuando comienza la ganaderización extensiva e intensiva, por dos razones: el bajo rendimiento de la milpa y la entrada de nuevos propietarios, 
muchos de los cuales provenían de la clase alta yucateca, que habían dejado las haciendas henequeneras. Así comenzó un decremento en las tierras para cultivo, sobre todo Tizimín.

En este sentido, la ganadería fue incentivada debido a la desarticulación entre el gobierno federal y estatal y la industria henequenera, impactada de por sí por la entrada de las fibras sintéticas. Las instancias gubernamentales federales que en 1963 habían creado la paraestatal CORDEMEX, pocas décadas después dejaron de subsidiarla y se liquidó a los trabajadores para que ejercieran por su cuenta (Iglesias 1986). A ello se suma la migración rural a la ciudad de Mérida y la consecuente caída en la producción del henequén (Castilla 1989). De ese modo, a partir de los años los empresarios y la población se volcaron hacia el sector pecuario, y específicamente en el oriente de Yucatán al ganado vacuno.

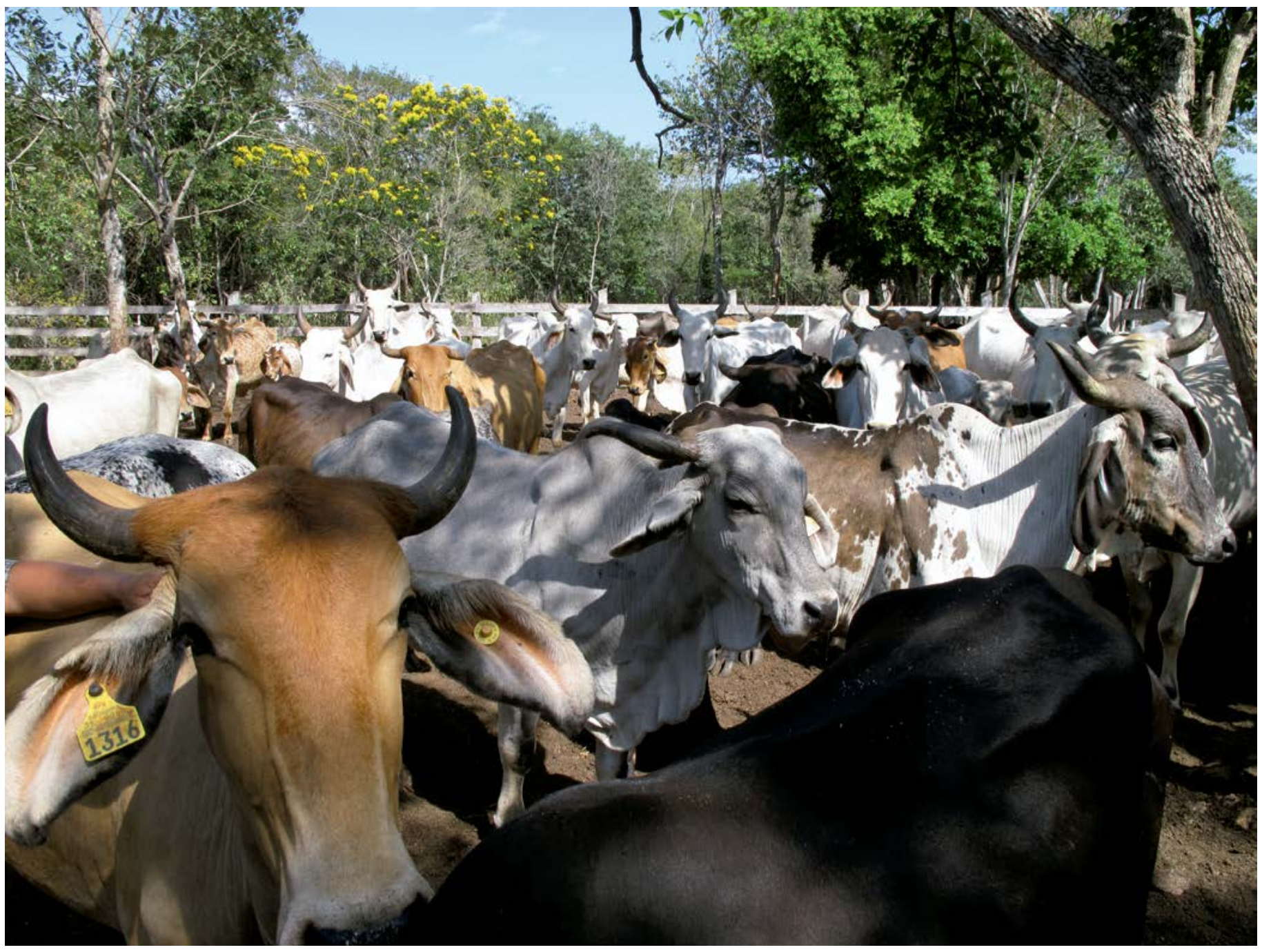


A pesar de que todas las actividades anteriores han tenido una gran influencia en la transformación del paisaje, ninguna ha sido tan determinante como la ganadería extensiva, ya que no respeta ningún tipo de vegetación ni vocación del suelo, y ha ido ensanchándose en toda la región (Sluyter 2001), con un impacto directo e indirecto en el entorno. El primero se relaciona con la deforestación de áreas para permitir el pastoreo del ganado. Se cambia el uso del suelo sin tomar en cuenta su aptitud natural; y el siguiente impacto es por el pastoreo en sí, ya que compacta en demasía el suelo y eso impide el crecimiento de cualquier tipo de planta. Por otro lado, el impacto indirecto proviene de las variedades de pastos que se cultivan, tales como estrella de África (Cynodon nlemfuensis), Taiwán (Penniseptum purpureum), brizantha (Brachiaria brizhanta) etc. (Ramírez y Rivera 2010), que remplazan de manera artificial la comunidad de herbáceas que deberían de dominar el campo oriental. Esto a su vez tiene un efecto secundario en la apicultura, ya que en la época de secas las abejas se alimentan de una herbácea dominante conocida como Tajonal (Viguiera dentata), la cual es repelida por los ganaderos bajo el argumento de su alta competitividad territorial.

Tizimín, Calotmul, Temozón y Río Lagartos se dedicaron a la ganadería extensiva, ya sea en ranchos privados o en ejidos (Ramírez 2006). Un claro ejemplo de su incremento se visualiza en Tizimín, que de tener 209554 cabezas en 1998 pasó a más de 260000 en 2005, un aumento de $24 \%$ en solo seis años. Si esto lo relacionamos con que para sostener una cabeza de ganado es necesaria una hectárea de terreno, quiere decir que en este periodo se han transformado más de 50000 ha (INEGI 1999, 2006). En las figuras 3 y 4 se aprecia la magnitud de este cambio, que fue a expensas de la vegetación secundaria derivada de la selva mediana subperennifolia, cuyo últimos relictos en Yucatán se encuentran precisamente en los municipios mencionados arriba. Cabe señalar que conforme la cartografía de uso del suelo y vegetación de 1976 a 2000, en Chemax se pasó de algunos parches utilizados para la ganadería a ocuparse en ello casi la mitad del territorio del municipio, lo cual, no obstante, no se ve reflejado en un incremento en la producción.

\section{LA SIEMBRA DEL MAÍZ}

Gran parte de la región oriental ha mantenido como actividad principal el cultivo de maíz. Luego de ser un sistema orientado a la subsistencia y haber pasado por diferentes etapas de comercialización, llegó ser parte de la producción de las ha- 
Figura 3. Tipos de vegetación y uso del suelo de los sitios de estudio en 1976. Elaboración propia.

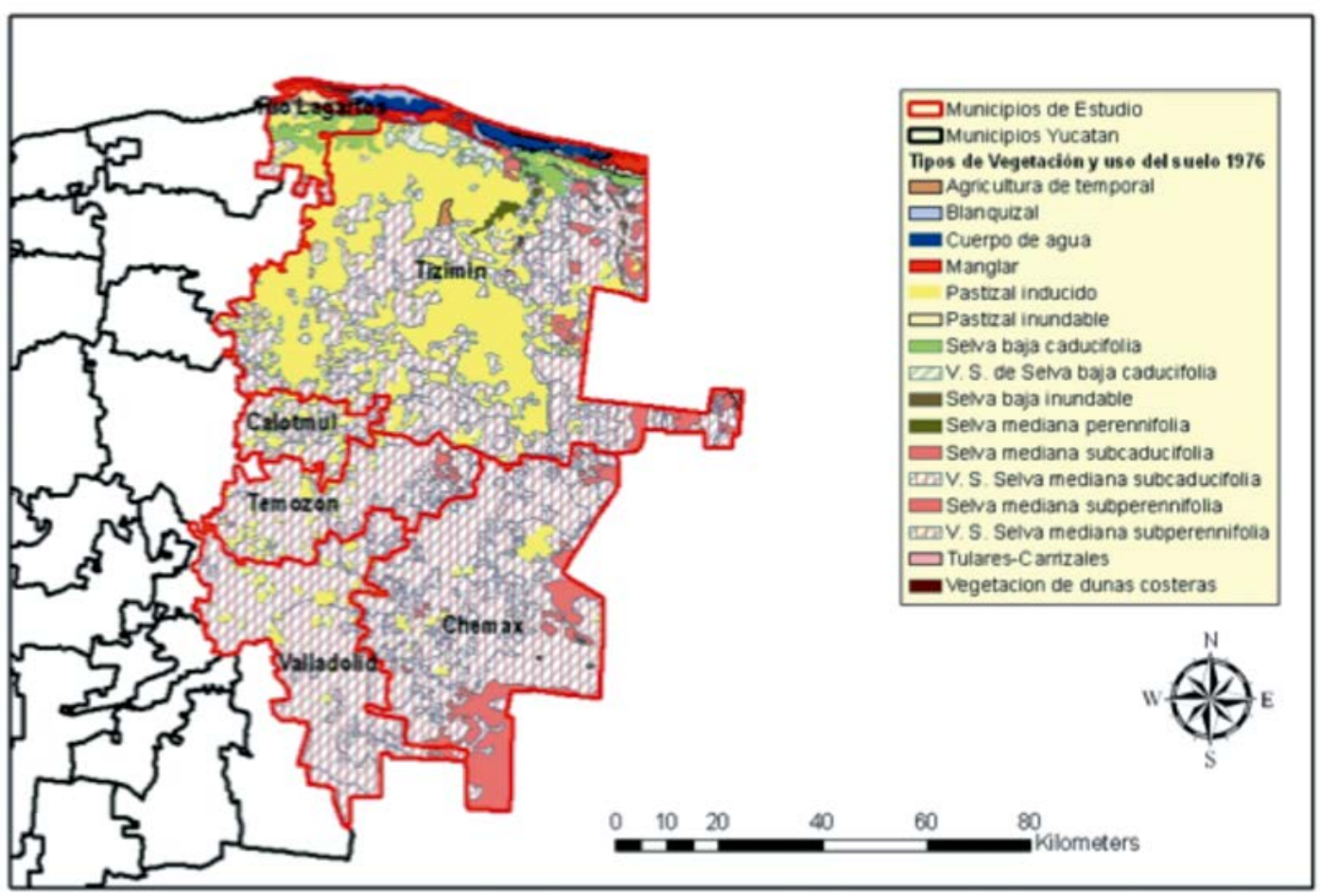

Figura 4. Tipos de vegetación y uso del suelo de los sitios de estudio en 2000. Elaboración propia

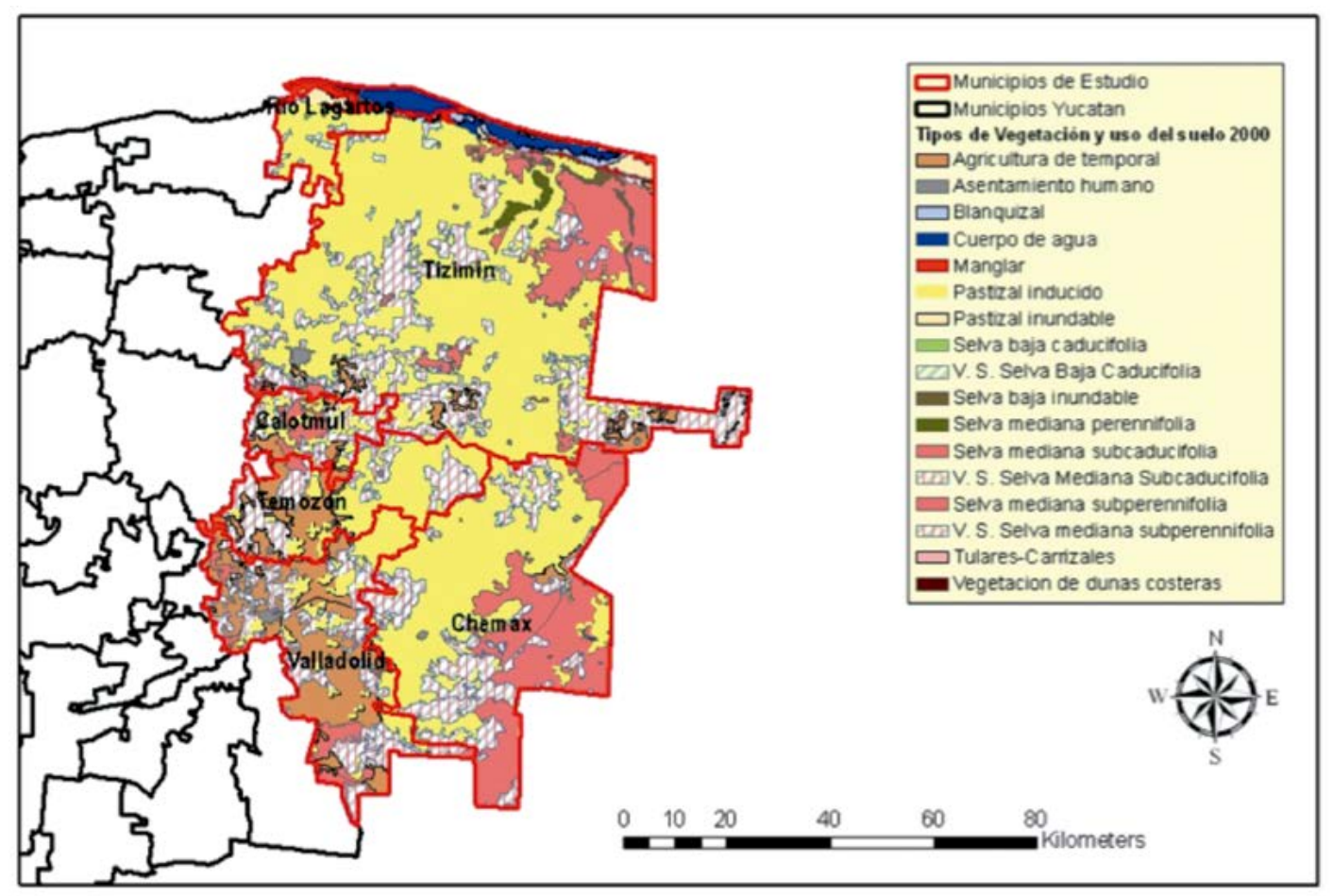


ciendas durante el siglo XIX (Challenger 1998). Sin embargo, su impacto ambiental ha sobrevenido por la modificación del sistema de roza, tumba y quema. Se ha venido reduciendo paulatinamente el tiempo de descanso entre una cosecha y otra, ${ }^{2}$ hasta volverse tan continuo que ha ido deteriorando la fertilidad del suelo (Ramírez 2003). Asimismo, en la forma de cultivo conocida como la milpa se ha ido reduciendo la diversidad de especies que antaño se vinculaban a ella.

Si bien los productores de maíz del oriente de Yucatán cultivan en promedio hasta dos hectáreas, la mayor parte de ellos siembra sólo algunos «mecates» (20x20m) para consumo propio, los cuales están mezclados con otras especies de plantas. Solamente los municipios del sur de la región de estudio (Valladolid y Chemax) continúan caracterizándose por tener mayores extensiones de cultivo, entre dos y cuatro hectáreas por productor, lo que se ve reflejado en las superficies sembradas por año (figura 5).

Figura 5. Hectáreas sembradas de maíz por año y por municipio. Fuente: INEGI 1999, 2003, 2008.

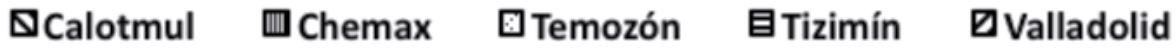

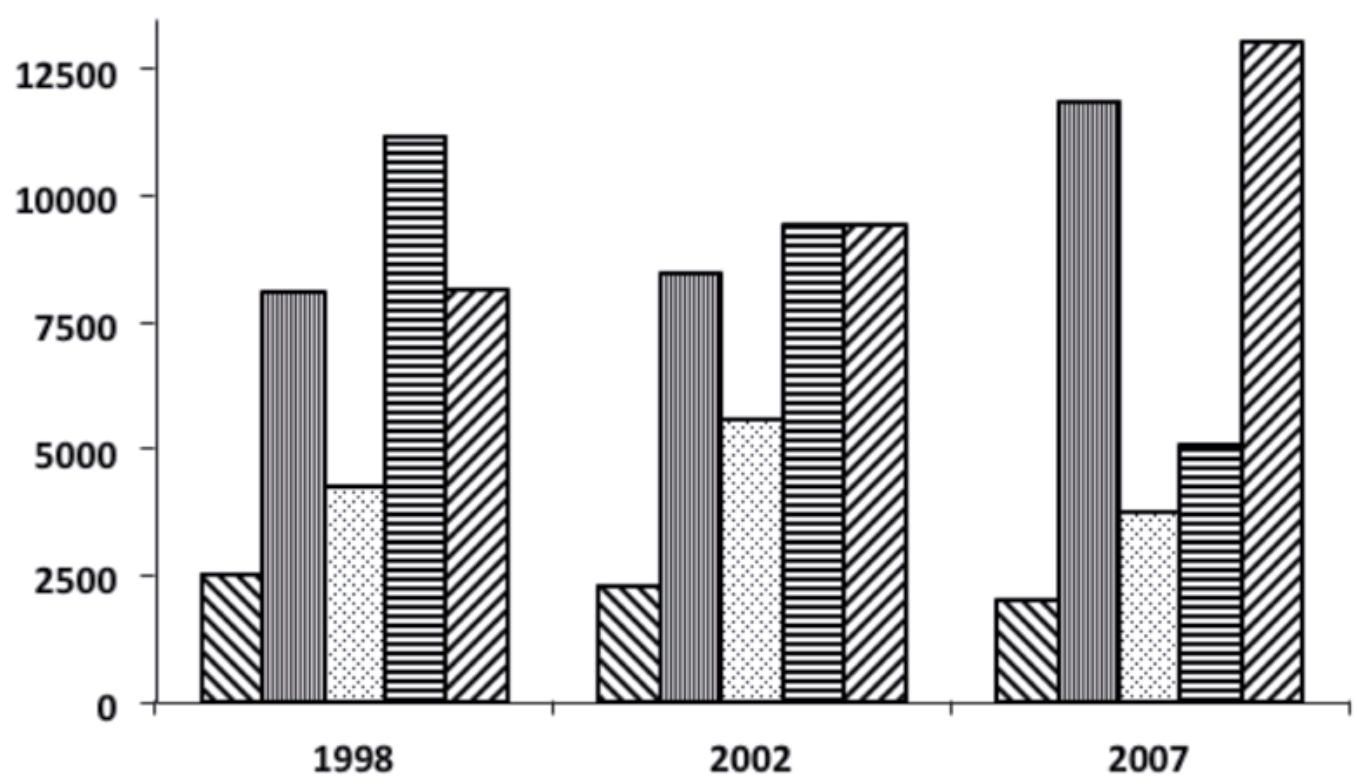

\footnotetext{
2 En este tiempo de descanso de la tierra conocido como acahual, la vegetación secundaria nativa surge de manera espontánea en terrenos preferentemente forestales que estuvieron bajo uso agrícola o pecuario en zonas tropicales.
} 
Según los pobladores, la baja producción de maíz está asociada actualmente con altos costos pues al desembolso para la erradicación de hierbas que compiten con los cultivos, sobre todo en etapas tempranas, debe invertirse en nutrientes para el suelo y en el exterminio de las plagas. En este último punto, los plaguicidas se utilizan muchos casos sin el seguimiento adecuado de las indicaciones, ya que se utilizan dosis mayores a las recomendados por los técnicos agrícolas, y su precio se eleva debido a que los insecticidas son muy específicos, es decir, están diseñados para atacar a un solo tipo de insecto, por lo que si los cultivos son depredados por varios, los gastos se multiplican. Todo ello ha influido para que muchos estén pensando en abandonar la siembra de la milpa.

\section{LA COSECHA DE SAL}

Otra actividad contemplada es la cosecha de sal en las costas yucatecas, particularmente en los municipios de Tizimín y, en mayor magnitud, en Río Lagartos. Esta práctica en el litoral yucateco también tiene su origen en la época prehispánica (Roche 1998), y en la actualidad es causa de alteraciones ecológicas. Si bien en el pasado se extraía en forma artesanal el cloruro de sodio al desecarse las charcas (con palas de madera) (Cortés 2012), desde mediados del siglo XX se realiza una extracción a gran escala por parte de la empresa privada de la familia Roche, que ha alcanzado a ser el segundo abastecedor a nivel nacional después de Guerrero Negro (Roche 1998) y que ha impactado negativamente en la costa oriental del estado puesto que el desecado de las ciénagas y la destrucción de los manglares para la explotación de la sal altera y afecta la vida de todas las especies asociadas a estos hábitats (Batllori et al. 1998).

La industria salinera comenzó en 1945 con 20 hectáreas y para el año de 2007 ya eran más de 2000 las que se ocupaban por parte de la empresa ISYSA, aunque la concesión incluye 5000 ha. Si bien la actividad salinera fue en un principio con mano de obra artesanal e intensiva, posteriormente el proceso se mecanizó y se hizo no solo intensivo sino extensivo, tecnificado e industrializado. Y su impacto latente es el rebose de los bordos de las charcas hipersalinas que podrían afectar al resto de los ecosistemas lagunares aledaños.

No obstante, debido a la gran importancia que se observó en los parches de hábitat natural que se vislumbraban en el paisaje de la zona costera oriental, en la que se incluye la salinera, en 1979 se decretó el Área Natural Protegida 
denominada Zona de Refugio Faunístico de Ría Lagartos, y posteriormente fue recategorizada en el año 2000 como Reserva de la Biosfera (Conanp 2007). Con ello se dio una oposición entre los ordenamientos de las autoridades federales por la zonificación de la reserva (zonas de conservación y amortiguamiento) y las zonas de la salinera industrializada (zonas de evaporación y cristalización), ya que en el plan de manejo se delimitan los linderos entre la reserva y las charcas concesionadas a la empresa. Y en forma paralela a esta discusión se dio un conflicto diferente entre la empresa salinera y los pescadores del lugar, en que se manifestó que la empresa salinera invadía y cerraba charcas de manera artificial en donde se solía pescar o en donde se daba la reproducción y refugio de peces de la ría (Aguilar 1997).

\section{LAS GRANDES MIGRACIONES}

Otro suceso importante que cambió la dinámica del oriente fue la apertura en los años setenta del turismo en las costas quintanarroenses, primero en Cancún y posteriormente en toda la Riviera Maya; con ello comenzó una gran migración temporal y permanente de la población que iba a trabajar en una diversidad de trabajos (construcción, cocina, meseros, etc.). Es más, los municipios de Valladolid y Chemax han aportado por varias décadas los mayores contingentes de personas que migran hacia la Riviera para los trabajos de hotelería y del ramo de la construcción, lo que llega a cambiar los valores mayas tradicionales, el orden económico, las expectativas de vida y consumo, el atuendo y los espacios domésticos y de tipo de vivienda (Ramírez 2006).

Aunado a ello, el impacto que derivó de la migración laboral de las personas hacia Estados Unidos y el vecino estado dio por resultado un abandono de muchas tierras, ya que la agricultura dejaba mucho menos dinero que lo que hacía la industria de la construcción. Es por ello que podemos observar en la cartografía de uso del suelo y vegetación una recuperación de las selvas medianas, sobre todo en el oriente de Chemax y Tizimín, al igual que en el sur de Valladolid (figuras 3 y 4). Muchas de estas tierras fueron abandonadas o rentadas a otros lugareños para que hicieran uso de ellas.

En la actualidad se vislumbra un decremento en la actividad de construcción en la Riviera Maya puesto que ya ha sido construido un gran número de hoteles y se hallan en funcionamiento. No obstante, la escasez de trabajo en estos sitios ha 
hecho que muchos de los migrantes pendulares yucatecos tengan que retornar a sus hogares en las poblaciones del oriente yucateco, y con ello a las actividades que antes desarrollaban (adultos mayores) y aun existen jóvenes que nunca se habían dedicado al cultivo de la tierra y lo harán por primera vez.

\section{REFLEXIONES FINALES Y CONCLUSIONES}

Los cambios ambientales que se dieron en el oriente de Yucatán durante el siglo XX respondieron a diferentes actividades productivas a las que se fueron sumando la disponibilidad de recursos del entorno y la capacidad económica de los empresarios que fueron incursionando en ellas. Tanto en el corte de la madera como en la colecta del chicle y en la explotación de la sal, se aprovechó el conocimiento que se tenía del entorno; por ejemplo, la madera era utilizada como material de construcción por los pobladores de la región desde antes de que existiera la compañía maderera; lo mismo podría decirse de la sal, que fue empleada dese la época prehispánica como condimento y preservador de alimentos.

Por lo que concierne a la otrora económicamente importante industria henequenera - que si bien para el oriente de Yucatán no tuvo gran extensión de cultivo-, que pasó por varias etapas, de ser de los exhacendados a convertirse en una paraestatal, para finalmente ser abandonada, dejó el paso a la ganadería como una apuesta de empresarios y pobladores, amén de contar con el apoyo por parte del gobierno estatal (García y Morales 2000). Con esto que se constata que en ocasiones las actividades productivas pueden ser impactadas positiva o negativamente por los apoyos gubernamentales y las políticas públicas, en este caso, después de una fallida intervención del aparato estatal en un sistema agrícola, el sistema henequenero, se desmantela y se resuelve apoyar otro sector productivo distinto.

Los cambios en el uso del suelo en el oriente también han respondido a otros aspectos sociales, como la migración laboral. En el caso de la empresa chiclera, los cortadores iban a las monterías durante la época de corte y retornaban a sus hogares posteriormente. Este tipo de migración no fue desconocida para los municipios del oriente al momento en que se comenzó a edificar Cancún y la Riviera Maya, y se produjo la expulsión de individuos (principalmente trabajadores de la construcción) a quienes ya no les redituaba económicamente lo que cosechaban de su milpa. A la par de ello, las tierras que dejaron los migrantes en su tránsito 


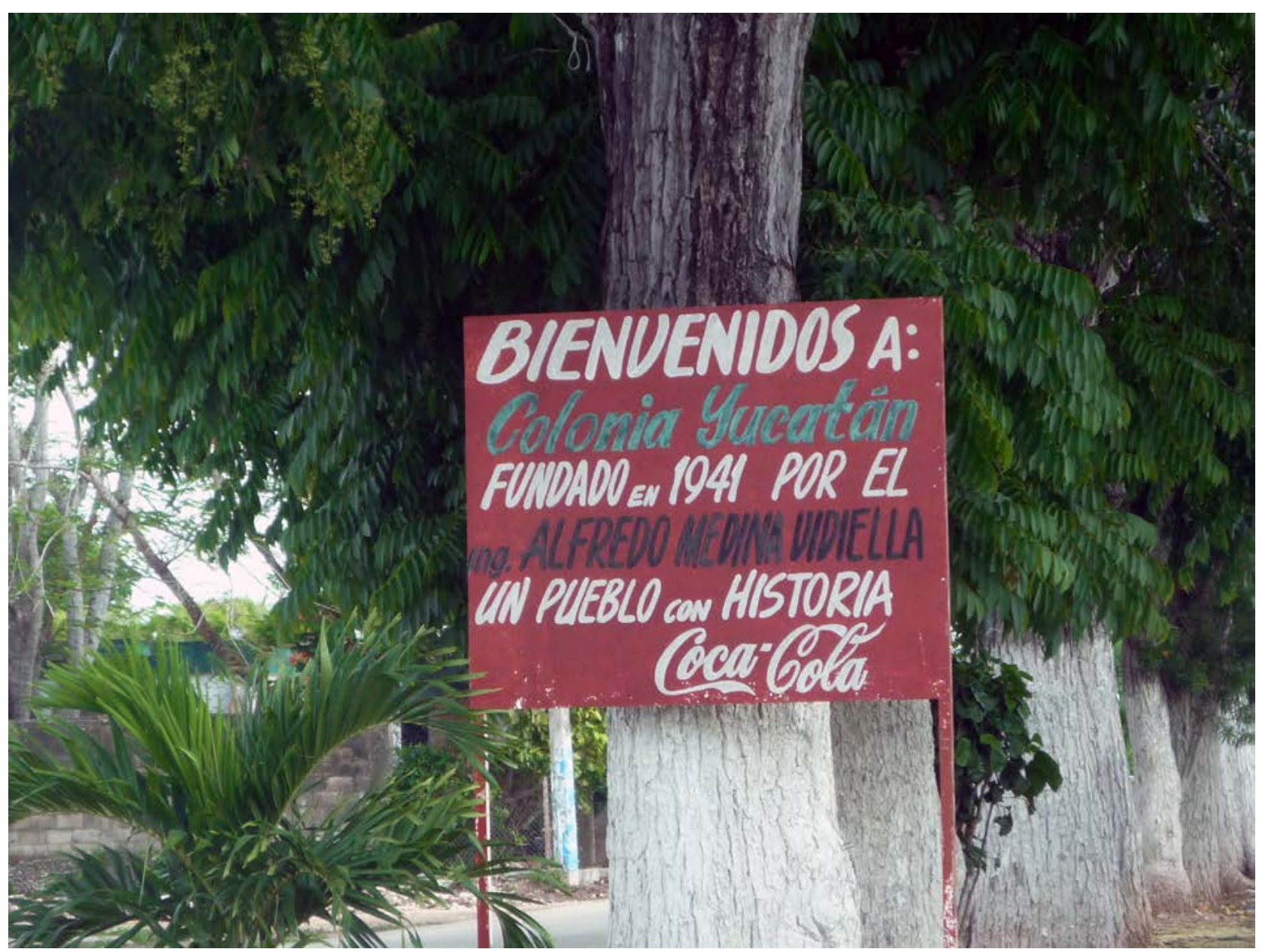

al extranjero o al estado vecino se quedaron en descanso, por lo que se pudo ver una recuperación temporal de la vegetación secundaria. En otros casos, las tierras se rentaron a otros ejidatarios para su cultivo, sobre todo en los municipios de Valladolid y Chemax.

Así se fueron modificando los paisajes del oriente del estado de Yucatán a lo largo del siglo XX. A los parches de hábitats con vegetación primaria en la cual se escindían especímenes del zapote para extraer chicle, con el respectivo impacto progresivo (pueblos enteros migraron pendularmente para esta actividad) le sucedió la introducción de la industria maderera, primero como empresa particular y luego como unión de ejidos, con la consecuente transformación de la selva mediana. Se comenzó con el corte de maderas preciosas para hacer tablones, pero con el paso de los años ya no discriminaban en la madera que cortaban ni en los sitios de donde la tomaban. Llegaron a abarcar así una mayor parte de la región oriente, y se ocasionó que ese tipo de selva quedara en relictos, lo cual se 
constata por medio de la vegetación secundaria que allí empezó a crecer y que es diferente en cuanto a diversidad y composición vegetal.

Pero el mayor impacto paisajístico se dio gracias a la ganadería extensiva y al cultivo de pastura. A esto vino a sumarse, en 1992, la modificación del artículo 27 constitucional, con lo cual se legitimó la venta de tierras ejidales a particulares a través del PROCEDE (Programa de Certificación de Derechos Ejidales y Titulación de Solares) (Procuraduría Agraria, 2016), y que a su vez se formaran minifundios de ejidatarios que compraron tierras a otros ejidatarios o de propietarios ajenos al ejido.

He presentado un panorama del uso de recursos naturales en poco más de 100 años en el oriente de Yucatán. Todo lo aquí referido ha dejado una huella en diferente grado, desde aquello que solamente dejó parches de vegetación parcialmente impactados hasta las actividades que han repercutido en grandes extensiones de terreno, y que han modificado tanto el paisaje como la diversidad de organismos asociados a este. Por otro lado, también las variables sociales han tenido una influencia en la transformación, en donde la migración tanto a los Estados Unidos como al vecino estado de Quintana Roo han repercutido de manera inversa, ya que su ausencia temporal ha permitido que se recupere la vegetación secundaria de selvas, e incluso que crezcan los remanentes. No obstante, la disminución en la captación de esta fuerza de trabajo ha hecho que familias enteras regresen a su tierra natal y que comiencen a hacer nuevamente uso del entorno.

\section{FUENTES DE CONSULTA}

Aguilar Cordero, Wilian, 1997, «Disputas y reclamos en un Área Natural Protegida: Pescadores Vs Industria Salinera», en Esteban Krotz (comp.), Aspectos de la cultura jurídica en el campo yucateco, Mérida, Maldonado/UADY/Seminario de Estudios de la Cultura-Conaculta, pp. 141-157.

Batllori, Eduardo, José Febles Patrón, Carmen Díaz Novelo y Miguel Briceño Quijano, 1998, "Condiciones ambientales relacionadas con la actividad salinera en el estado de Yucatán», en Juan Carlos Reyes (ed.), La sal en México II, México, Secretaría de Cultura de Colima/Universidad de Colima/Dirección General de Culturas PopularesCNCA, pp. 323-330.

Castilla, Beatriz, 1989, "La organización de la fuerza de trabajo en Yucatán 1895-1980», Revista de la Universidad Autónoma de Yucatán, 4(170), pp. 39-53.

Comisión Nacional de Áreas Naturales Protegidas, 2007, Programa de Conservación y Manejo Reserva de la Biosfera Ría Lagartos, México, ConANP. 
Cortés, Inés, 2012, «Aspectos agrarios de la producción de sal en Yucatán en el presente neoliberal», Temas Antropológicos, Revista Científica de Investigaciones Regionales, 34(2), pp. 101-127.

Challenger, Antony, 1998, Utilización y conservación de los ecosistemas terrestres en México. Pasado, presente y futuro, México, CONABIO/INBIO-UNAM/Agrupación Sierra Madre.

Dampier, William, 1789, A new voyage round the world, Londres, disponible en <gutenberg.net.au/ebooks05/0500461h.html>.

Forman, Richard, 1999, Land mosaics. The ecology of landscapes and regions, Cambridge University Press.

García de Fuentes, Ana y Josefina Morales, 2000, «Dinámica regional de Yucatán 19802000», Investigaciones geográficas, 42, pp. 157-172.

Iglesias Lesaga, Esther, 1986, "Dificultades y posibilidades de Cordemex», Momento Económico, 22, pp. 7-12.

Instituto Nacional de Estadística y Geografía, 1999, Anuario estadístico de Yucatán, México, INEGI.

2003, Anuario estadístico de Yucatán, México, INEGI.

2006, Anuario estadístico de Yucatán, México, INEGI.

2008, Anuario estadístico de Yucatán, México, INEGI.

2009, Anuario estadístico de Yucatán, México, INEGI.

Jeffrey, Amy y Carlos Echazarreta, 1996, «Medical uses of honey», Revista Biomédica, 7(1), pp. 43-49.

Leff, Enrique, 2004, «Vertientes y vetas de la historia ambiental: una nota metodológica y epistemológica», Anuario del Instituto de Estudios Histórico-Sociales, 19, pp. 133-145.

Machuca Gallegos, Laura, 2010, «Los hacendados y rancheros mayas de Yucatán en el siglo XIX», Estudios de Cultura Maya, 36, pp. 173-200.

2011, Los hacendados de Yucatán 1785-1847, México, CIESAS (Publicaciones de la Casa Chata).

Montalvo Ortega, Enrique e Iván Vallado Fajardo, 1997, Yucatán: sociedad, economía, política y cultura, México, Centro de Investigaciones Interdisciplinarias en Ciencias y Humanidades-UNAM.

Pinet, Plasencia Adela, 1998, La península de Yucatán en el Archivo General de la Nación, México, Archivo General de la Nación/Centro de Investigaciones Humanísticas de Mesoamérica-UNAM/Gobierno del Estado de Chiapas.

Pinkus Rendón, Miguel, Jorge León Cortés y Guillermo Ibarra Núñez, 2006, «Spider diversity in a tropical hábitat gradient in Chiapas, Mexico», Diversity and Distributions, 12, pp. 61-69.

Pinkus-Rendón, Miguel, Víctor Parra-Tabla y Virginia Meléndez-Ramírez, 2005, «Floral resource use and interactions between Apis mellifera and native bees in cucurbit crops in Yucatán, México», The Canadian Entomologist, 137, pp. 441-449.

Ponce-Jiménez, Martha, 1990, «La montaña chiclera Campeche: Vida cotidiana y trabajo (1900-1950)», México, CIESAS (Cuadernos de la Casa Chata, 172), pp. 1-233. 
Procuraduría Agraria, 2016, Procede, <www.pa.gob.mx/publica/pa070113.htm> [consulta: 18 de marzo de 2016].

Ramírez Carrillo, Luis Alfonso, 2003, «Yucatán», en Mario Ruz (coord.), Los mayas peninsulares. Un perfil sociodemográfico, México, UNAM (Cuadernos del Centro de Estudios Mayas, 28), pp. 47-77.

_ 2006, «Impacto de la globalización en los mayas yucatecos», Estudios de Cultura Maya, 27, pp. 73-97.

Ramírez Cancino, Laura y Juan Rivera Lorca, 2010, «La ganadería en el contexto de la biodiversidad», en Rafael Durán García y Martha Méndez González (eds.) Biodiversidad y Desarrollo Humano en Yucatán, Mérida, Yucatán, CICY/PPD-FMAM/Conabio/Seduma, pp. 106-108.

Rivera-Ayala, Clara, 2001, "La exportación de maderas y chicle en el puerto de Tuxpan, Veracruz, 1870-1900», Sotavento, 9, pp. 49-88.

Roche, Joaquín, 1998, «Producción y comercialización de la sal en la península de Yucatán. Un relato testimonial», en Juan Carlos Reyes (ed.), La sal en México II, México, Secretaría de Cultura de Colima/Universidad de Colima/Dirección General de Culturas Populares-CNCA, pp. 323-330.

Ruíz-Silva, José, 2011, Colonia Yucatán. La historia reciente de un pueblo maderero, Mérida, Yucatán, Fundación Amigos de la Colonia Yucatán.

Ruz, Mario, 1979, «El añil en el Yucatán del siglo XVI», Estudios de Cultura Maya, 12, pp. 111-156.

Sluyter, Andrew, 2001, «Ganadería española y cambio ambiental en las tierras bajas tropicales de Veracruz, México, siglo XVI», en Lucina Hernández (comp.), Historia ambiental de la ganadería en México, México, Institut de recherrche pour le développement/Instituto de Ecología, pp. 25-40.

Summerville, Keith y Thomas Crist, 2001, «Effects of experimental habitat fragmentation on patch use by butterflies and skippers (Lepidoptera)», Ecology, 82(5), pp. 1360-1370.

Sweeney, Lean, 2006, La supervivencia de los bandidos. Los mayas icaiches y la política fronteriza del sureste de la península de Yucatán, 1847-1904, México, UNAM.

Taracena, Arturo y Miguel Pinkus, 2010, Cartografía histórica de la península de Yucatán S. XIX y XX, Mérida, CEPHCIS-UNAM.

Terán Silvia y Christian Rasmussen, 1994, La Milpa de los Mayas, Mérida, DANIDA-CICY. 2005, Xocén, Un pueblo en el centro del mundo, Mérida, Universidad Autónoma de Yucatán.

Toledo, Víctor Manuel, Narciso Barrera-Bassols, Eduardo García-Frapolli y Pablo AlarcónChaires, 2008, «Uso múltiple y biodiversidad entre los mayas yucatecos (México)», Interciencia, 33, pp. 345-352.

Fecha de recepción: 27 de octubre de 2015

Fecha de aceptación: 28 de marzo de 2016 